\title{
Snow-cover depth, distribution and duration data from northeast Greenland obtained by continuous automatic digital photography
}

\author{
Hanne H. Ghristiansen \\ Institute of Geography, University of Copenhagen, Øster Voldgade 10, 1350 Copenhagen, Denmark
}

\begin{abstract}
Detailed data on autumn, winter and spring snow-cover conditions from remote areas are often difficult or very expensive to obtain. Therefore, an inexpensive method of digital photography was tested in high-Arctic Greenland. Automatic digital photography has provided daily data on snow distribution and snow depth for $>1$ year from the Zackenberg area $\left(74^{\circ} 30^{\prime} \mathrm{N}\right)$ in northeast Greenland. A standard digital hand-held camera (Kodak Digital Science DC50) was equipped to become automatic; it is supplied with an "automatic finger" and an external power supply and built into a protecting box with additional solar panels on top, in order to secure continuous operation throughout the year. The daily photograph covers a $100 \mathrm{~m}$ transect through a seasonal snowpatch, and thus on an annual basis also yields information on snow-cover duration in the different vegetation zones of the snowpatch. The camera was installed in mid-August 1998. Photographs from the period mid-August 1998 to early September 1999 were collected and analyzed. All photos are taken at astronomic noon in order to use the daylight as long as possible into the winter season before the $24 \mathrm{~h}$ winter darkness begins in mid-November.

The digital photographs yielded the following information for the year 1998/99: The first winter snowfall occurred on 18 October; small-scale snow redistribution by snowdrifting started when the winter snow cover was about $5 \mathrm{~cm}$ thick. The continuous winter snow cover lasted for a minimum of 170 days in the most snow-deprived areas downwind of the snowpatch, whereas snow in the centre of the snowpatch stayed on the ground for $>325$ days, turning the snowpatch perennial in summer 1999.

Meteorological data obtained close to the photographed snowpatch site, in combination with the snow-cover depth and distribution data derived from the photographs, show that at wind speeds (at $2 \mathrm{~m}$ height) of up to around $6 \mathrm{~m} \mathrm{~s}^{-1}$, only small-scale snowdrifting took place, when the snow cover was thin. Intense snowdrifting, however, took place at wind speeds of $8-13 \mathrm{~m} \mathrm{~s}^{-1}$, particularly when enough snow was available in the upwind area. The automatic continuous photography technique demonstrated here could be particularly useful in remote areas at high risk of avalanches during winter. It is an alternative to traditional snow monitoring achieved mainly by sonic sensors, snow pillows or manual measurements of snow depths. Likewise, it can provide better areal information than most standard methods, which give only point measurements.
\end{abstract}

\section{INTRODUCTION}

Snow-cover depth, distribution and duration data are important for improving knowledge of climate-change effects in Arctic landscapes, and especially for understanding the physical processes associated with snow redistribution, which is essential for improving snowdrift modelling (Liston and Sturm, 1998). In addition, palaeoclimatic reconstructions based on sediment studies from nival basins or fans could be improved if more knowledge of modern meteorological controls on snowpatch development and interannual variation were obtained (Christiansen, 1998a).

In most periglacial and glacial environments, precipitation falls mainly as snow during winter. The air temperature is usually $<0^{\circ} \mathrm{C}$, and snow is redistributed by snowdrifting when the wind speed increases above the transport threshold velocity. Therefore, much snow is redistributed into snow- drifts accumulating in topographically and meteorologically determined lee sites.

Continuous monitoring of snow-cover conditions during winter in periglacial and glacial environments is a challenge which modern technology is helping to solve. Direct snowdepth measurements in remote areas have mainly been obtained from sonic sensors, snow pillows or manual measurements using poles. These techniques are, however, relatively expensive and provide data from no more than a few points, excluding information on the spatial distribution and duration of snow on the landscape scale. Satellite photographs do not work on a scale detailed enough to register snowpatch accumulation and ablation, and aerial photographs are seldom recorded on a more frequent than annual basis.

In the present paper a new automatic, digital photography technique is presented and tested in a remote high-Arctic site, the Zackenberg area in northeast Greenland. The results 


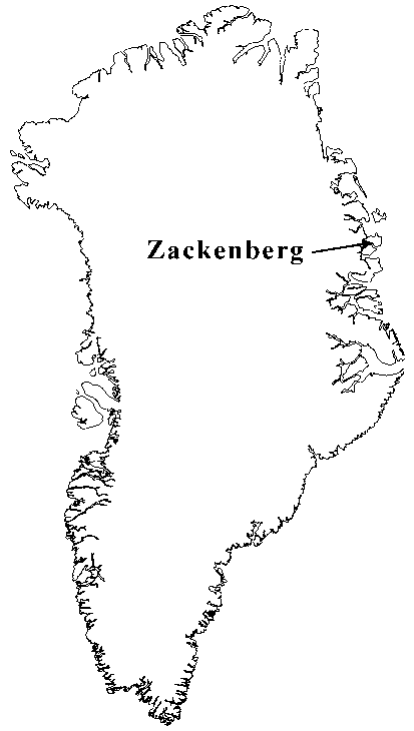

Fig. 1. The location of the Zackenberg area in Greenland.

of the first year of operation, from summer 1998 to early autumn 1999, are presented, including some data on snow depth and duration.

\section{STUDY AREA}

The Zackenberg area is situated at $74^{\circ} 30^{\prime} \mathrm{N}$ (Fig. 1), in the continuous permafrost zone of high-Arctic northeast Greenland. Topographically the area is dominated by a large southfacing, wide valley, Zackenbergdalen, with glacial landforms in a low-relief landscape. Snowpatches have predominantly southerly aspects, indicating the strong control by the northerly winter winds on their location (Christiansen, 1998b). The Zackenberg research station, which is located in the lower part of Zackenbergdalen, is part of Zackenberg Ecological Research Operations (ZERO) (Rasch, 1999), but it is manned only during the summer season.

In the middle of Zackenbergdalen is a sonic range sensor for snow-depth measurements, part of the ClimateBasis monitoring programme at Zackenberg (Rasch, 1999). There are no other direct continuous observations of snow depth. The ClimateBasis programme at this site also includes a standard meteorological station. Wind speed, wind direction, air temperature and precipitation from this station have been used in this study to interpret the meteorological control on the snow-distribution data obtained from the automatic camera photographs.

In an active-layer monitoring grid, called ZEROCALM2 (Christiansen, 1999), the automatic camera has been photographing a seasonal snowpatch transect (Fig. 2). This site was chosen because of a distinct vegetation zonation controlled by snow duration (Christiansen, 1996). Direct snow-depth measurements were easily obtained together with active-layer thaw progression data during summer, just as ground-temperature measurements were carried out in the same transect through the snowpatch for some years. The ZEROCALM2 grid is located about $750 \mathrm{~m}$ south-southwest of the meteorological station. The photographed snowpatch is placed on the southern, lee side of a fluvial terrace. It accumulates here, like most snowpatches in the Zackenberg area, due to dominant northerly winter winds (Christiansen, 1998b).

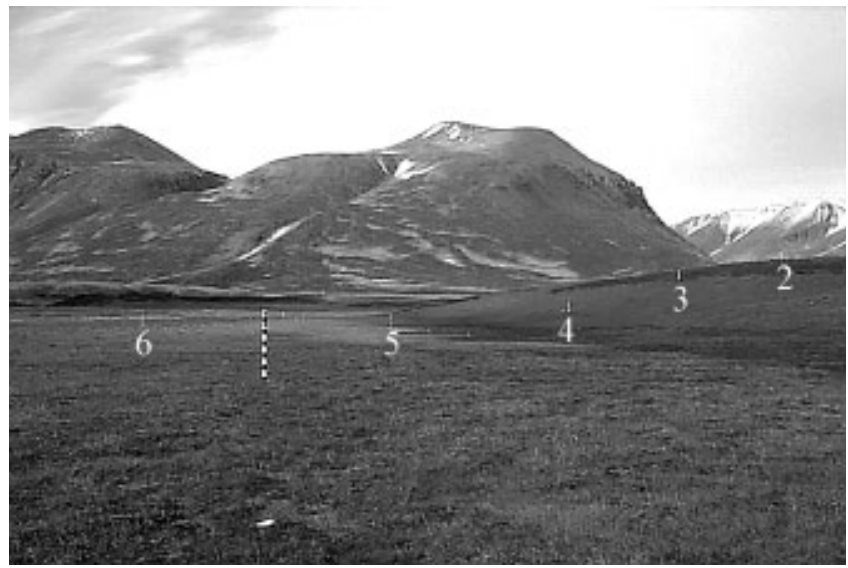

Fig. 2. The automatic digital photograph from the ZEROCALM2 grid in the Zackenberg area, 18 August 1998, with measuring sticks located at vegetation limits in a transect through the snowpatch site. The photographed transect is about $100 \mathrm{~m}$ long. The distance from the camera to sticks 2-6 varies from $65 \mathrm{~m}$ to $105 \mathrm{~m}$. The stick in the foreground, with $10 \mathrm{~cm}$ intervals, is only $15 \mathrm{~m}$ from the camera. The photograph is taken towards the northwest. Seen in the background are the southeast side of the Zackenberg mountain, reaching 1360 m a.s.l., and, to the right, further distant parts of the Dombjerg mountain (1300 m a.s.l.).
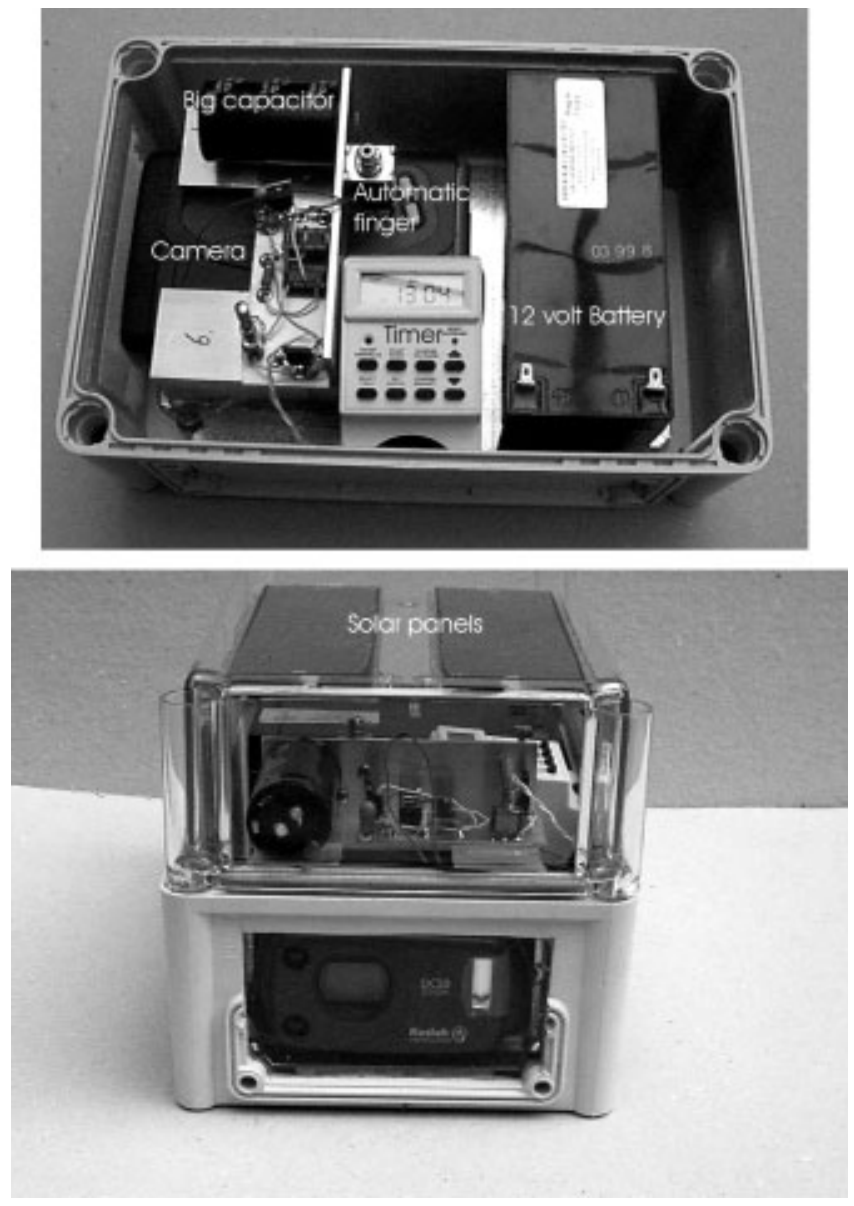

Fig. 3. The automatic camera, with its timer, automatic finger and $12 \mathrm{~V}$ battery, in the lower part of the weatherproof box. Below, the camera front is seen through the plastic glass window in the weatherproof box, which protects the camera lens from snow and rain. On top of the box the solar panels can be seen. 


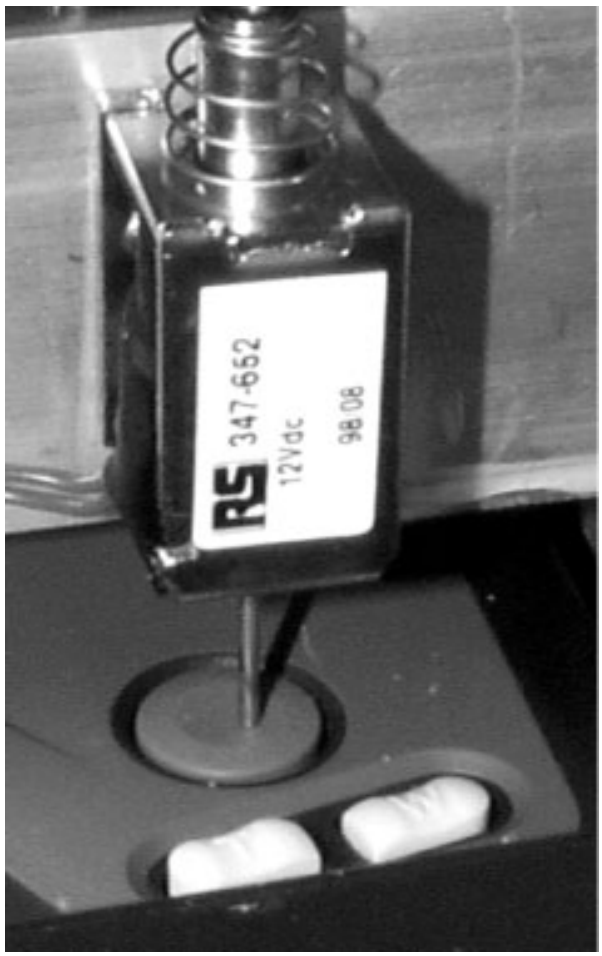

Fig. 4. Close-up of the automatic finger mounted over the camera shutter-release button.

\section{THE AUTOMATIC CAMERA}

A standard hand-held Kodak Digital Science DC50 zoom camera was used, with a $30 \mathrm{MB}$ CompactFlash card for storing the photographs. The operating environment promised by Kodak is only $0^{\circ}$ to $+40^{\circ} \mathrm{C}$. Several external units, comprising standard, easily available low-cost products, were connected to the camera to enable continuous automatic operation. A $12 \mathrm{~V}$ battery, connected to two solar panels, secured a continuous power supply. An "automatic finger" allowed the shutter-release button to be pushed, thus taking the photographs (Fig. 3). The automatic finger consists of a watch, an electronic timer and a short stroke solenoid (Fig. 4). The watch is an ordinary time switch called Ideline and is a standard low-cost product that simply turns the power supply on and off. It has been modified to work at $12 \mathrm{~V}$ d.c. These devices were added without modifying the camera, so it can still operate as a normal hand-held camera if taken out of the weatherproof box into which the automatic camera is built.

When it is time to take a photograph four operations occur: (1) The watch turns on the power supply to the camera and the "automatic finger" electronics. (2) A timer starts a $30 \mathrm{~s}$ delay in which a d.c. - d.c. converter charges a big capacitor to $30 \mathrm{~V}$. (3) After the $30 \mathrm{~s}$ delay the capacitor is discharged through the short stroke solenoid, thus pressing down the shutter-release bottom on the camera, and the photograph is taken. (4) After another $30 \mathrm{~s}$, the watch turns off the power supply to the camera, and goes into stand-by mode until the next photograph has to be taken. Thus, it takes $1 \mathrm{~min}$ to take and store a photograph.

When not operating, the camera is in stand-by mode, using $0.2 \mathrm{~mA}$ of power, while during each $1 \mathrm{~min}$ of photography approximately $500 \mathrm{~mA}$ is used. Therefore, the total power consumption is around $13.1 \mathrm{mAhd}^{-1}$, or $4.8 \mathrm{Ah} \mathrm{a}^{-1}$. The solar panels fixed on top of the camera box can deliver up to $500 \mathrm{~mW}$ at an insolation of $1000 \mathrm{~W} \mathrm{~m}^{-2}$, and thus provide the

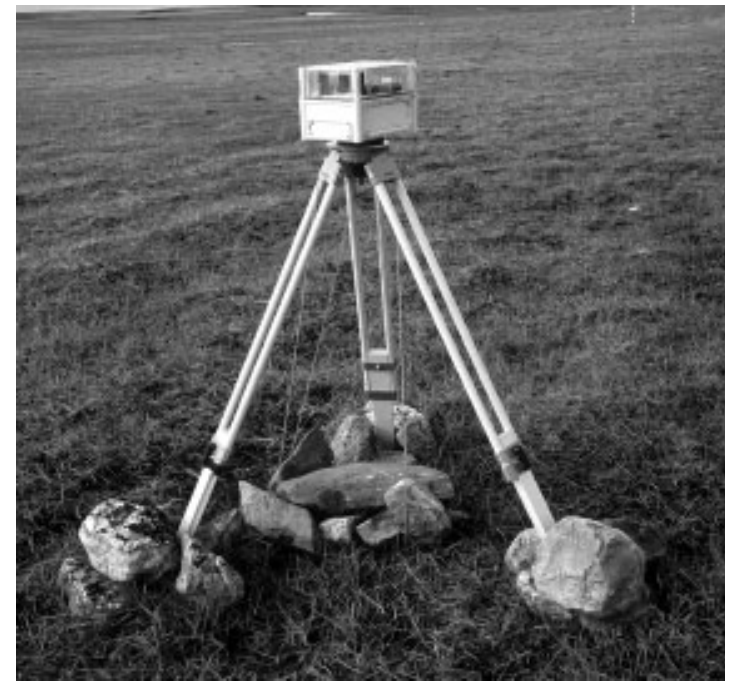

Fig. 5. The automatic camera in its box, mounted on top of the tripod at a height of $1.5 \mathrm{~m}$ above the terrain surface in the Zackenberg area.

$12 \mathrm{~V}$ battery with up to $42 \mathrm{mAh}$. It is very important that the battery is fully charged before the winter, with low temperatures and darkness, begins. This is the reason for the large over-dimensioning of the power supply. This set-up provided sufficient power for full operation during the 2 months of complete winter darkness, when air temperatures ranged between $-5^{\circ}$ and $-35^{\circ} \mathrm{C}$, and for a subsequent 3.5 month period when the camera was continuously buried in snow.

The costs of a camera including housing and additional materials to enable automatic operation are around GBP 1,100. The automatic camera was developed and tested at the Institute of Geography, University of Copenhagen, Denmark, by chief technician U. P. Thomas.

\section{GAMERA AND SNOW-REGISTERING SET-UP}

The camera was fixed on top of a tripod, which had its legs buried approximately $40 \mathrm{~cm}$ down through the active layer, into the top permafrost (Fig. 5). In addition, the tripod was secured with stainless-steel wire directly from the top platform down into the upper permafrost. Finally, boulders were built up around the tripod legs and below it, to prevent musk oxen from moving the camera. The camera was mounted at $1.5 \mathrm{~m}$ above the ground.

In the photographed snowpatch transect area five sticks were pushed about $30 \mathrm{~cm}$ into the ground (Fig. 2). Each stick was $5 \mathrm{~cm}$ wide and extended $120 \mathrm{~cm}$ above the ground surface. The sticks were painted red and white in $20 \mathrm{~cm}$ intervals. They were placed in a transect across the snowpatch site at the different vegetation limits, at distances of 65$105 \mathrm{~m}$ from the camera, so that the snowpatch depth and duration could be monitored at different parts of the snowpatch on a daily basis.

\section{THE PHOTOGRAPHS}

The camera watch was programmed to take the daily photograph at maximum sun elevation. For a full year of operation a medium photograph resolution of $680 \times 540$ pixels was used, enabling 360 photos to be stored on the CompactFlash card. The digital photographs were stored 
13-Oct 17-Oct 21-Oct 25-Oct 29-Oct 2-Nov 6.Nov 10-Nov 14-Nov 18-Nov

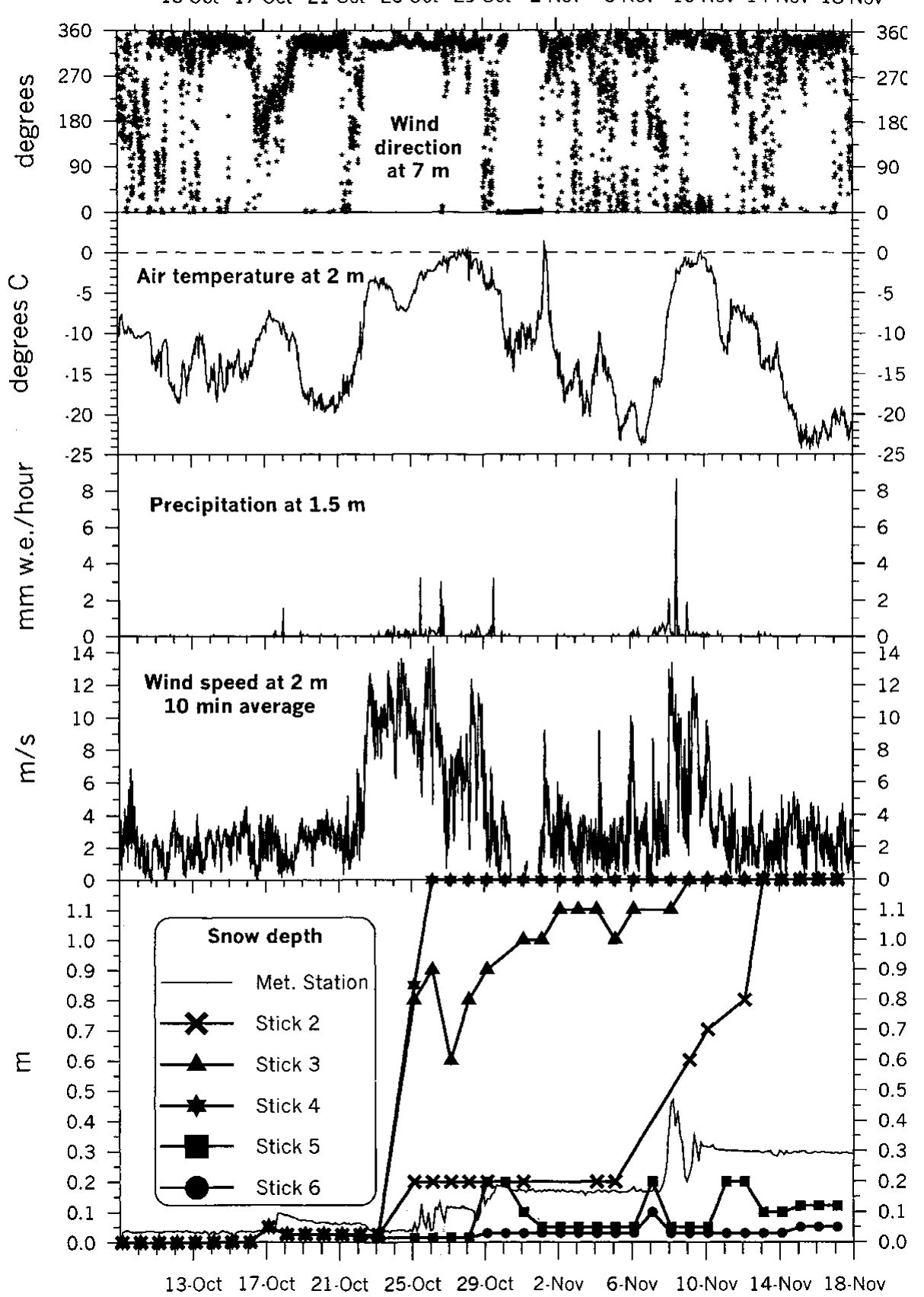

Fig. 6. Snow-depth readings from the sticks in the automatic digital photographs, together with meteorological data from the nearby meteorological station of the ClimateBasis monitoring programme for the period 10 October-18 November 1998. Each reading is marked by different symbols for each stick on the snow-depth curves. Snow-depth measurements every third hour from the Sonic Range sensor at the meteorological station are also presented as a thin line in the snow-depth graph. This curve starts at $4 \mathrm{~cm}$, which is the height of the vegetation at the measuring point before snowfall. The precipitation was measured using a heated Belfort instrument with a Nipher screen. Wind-speed and-direction data were recorded every 10 min, while air temperature and precipitation were logged every hour. Very few wind data were recorded during the period 30 October-1 November, due to technical problems with the sensors.

as Kodak digital camera format (KDC) files. They were offloaded from the CompactFlash card using PhotoEnhancer (vers. 2.1) in summer 1999. High-resolution tagged image file format (TIFF) files were generated from the KDC files, and these were analyzed using CorelDRAW software.

The photographed area (Fig. 2) covers the snowpatch area, with the distinct vegetation zones and its forefield. The backwall starts at stick 2, and the photo covers approximately $100 \mathrm{~m}$ along the transect, so it monitors the initial build-up and the final melting of the snowpatch. The characteristic dark vegetation zone dominated by Cassiope tetragona is located on the upper part of the snowpatch backwall, between sticks 2 and 3 (Fig. 2). Below the Cassiope tetragona zone is a lighter-coloured vegetation zone dominated by Salix arctica between sticks 3 and 4; mosses exist between sticks 4 and 5, and grasses from stick 5 and downslope in the transect.

The camera was set up on 18 August 1998, and has operated every day without problems until 7 September 1999, when photographs were last offloaded. It was located in the snowpatch forefield area, south-southeast of a small valley eroded into the fluvial terrace. This location prevents the camera from being placed in the thickest part of the snowpatch in winter. The stick immediately in front of the camera was already bent down by musk oxen on 22 October. Stick 5 was slightly bent southwards, either by the wind or by musk oxen, also in the early winter. In summer 1999, stick 4 was bent 


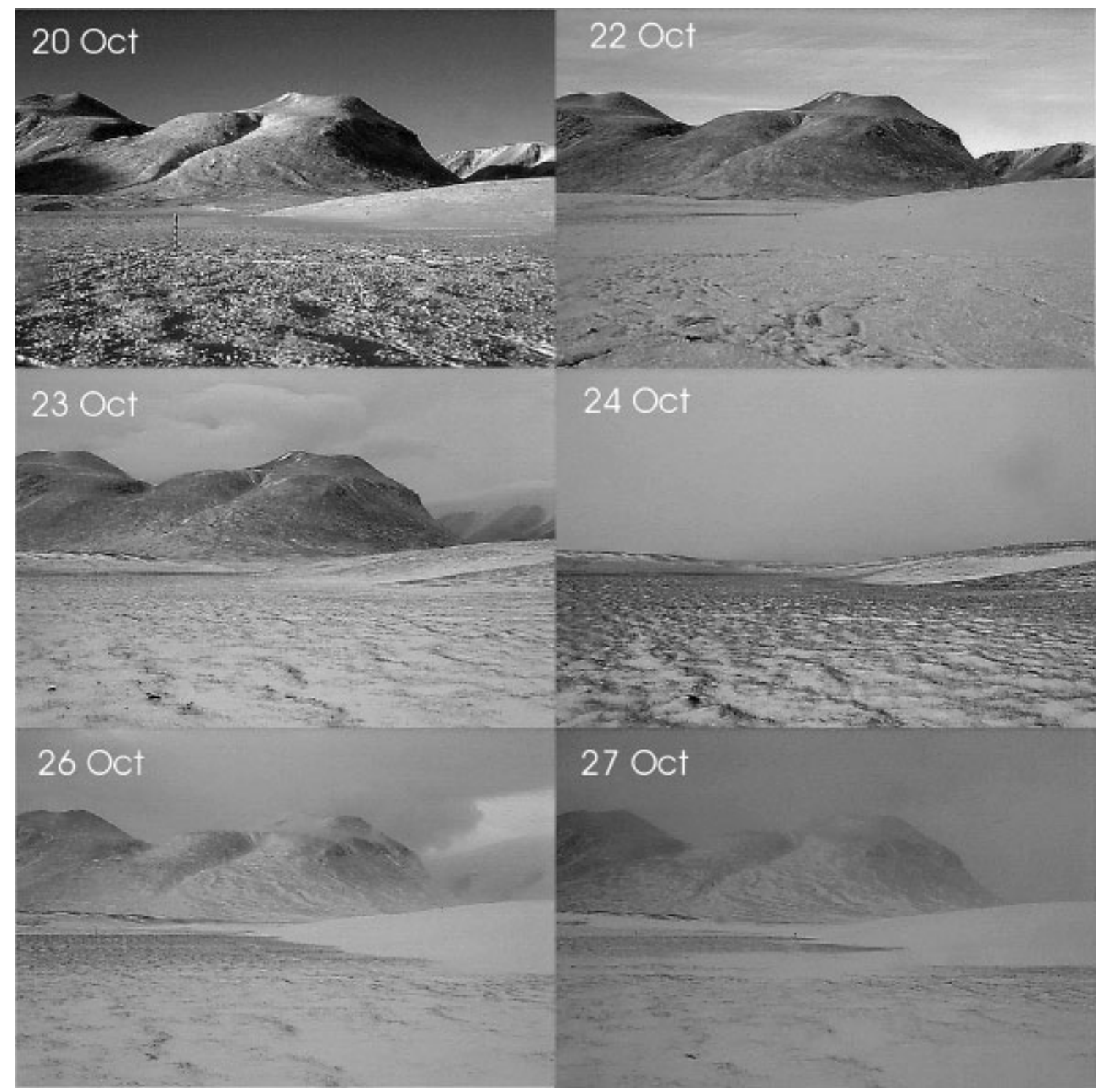

Fig. 7. Automatic digital photographs, 20-27 October 1998, covering the first snowdrifting period.

southwards, when the top of it melted free. It had, however, been standing upright until covered by snow in autumn 1998, and the displacement was presumably caused by snow creep.

Enough light was available on the photographs for snowdepth registering until 23 November and again from 25 January. The last photograph with sun still reaching the top of the Zackenberg mountain was taken on 4 November, while the first photograph with sun reaching the Zackenberg top was taken on 6 February. Directly available from the photographs is information on the general weather conditions such as cloud cover, basic level of the clouds, visibility, precipitation or not, precipitation type and positive or negative ground-surface temperature (frozen or not). More specifically, snow-cover depth, distribution and duration of the snowpatch in the ZEROCALM2 grid is monitored in the photographed area, with an accuracy of about $5-10 \mathrm{~cm}$.

Most photographs are useful even during snowdrift periods, mainly because the camera faces almost perpendicular to the dominant winter wind direction. Only when snowfall or snowdrifting were very dense could the sticks not be identified on the photographs.

The camera was completely buried in snow between 25 and 26 February during a period of strong winds and intense snowdrifting. It did not reappear above the snow surface until 10 June. During these 3.5 months the light level on the daily photographs still recorded significant changes, from completely dark to lighter conditions either from day to day or over longer periods. However, the opposite also occurred. Some of the most extreme daily light-level changes occurred during the period mid- to late May when wind speeds several times exceeded $10 \mathrm{~m} \mathrm{~s}^{-1}$ at $2 \mathrm{~m}$ above the ground at the meteorological station. These recordings from the buried camera suggest that the snow depth over the camera was reduced, and that snow was both eroded and deposited over the camera in periods with higher wind speeds.

\section{SNOW DEPTH AND DISTRIBUTION}

The most detailed data on snow depth in the different parts of the photographed snowpatch were obtained during the early winter period 10 October-18 November, when the measuring sticks were still partly free of snow, and the daylight still sufficient for reading the length of the sticks on the photographs. Due to different light conditions on the photographs, however, not all sticks could be seen clearly enough for the snow depth to be read on all days. At the snow-depth curves (Fig. 6) the symbols mark the individual readings of snow depth on the sticks.

Combining the snow depths with the meteorological 
data provides information on snowpatch accumulation control. The first snow fell on 17-18 October, when a homogeneous layer about $5 \mathrm{~cm}$ thick covered the entire landscape. Before this date, only rime had covered the vegetation. On 26 October a thicker snowdrift started accumulating (Fig. 6). At that time strong northerly winds with consistent speeds of around $8-13 \mathrm{~m} \mathrm{~s}^{-1}$ had lasted since 23 October, but little snow accumulated in the snowpatch area until 26 October (Figs 6 and 7). From the first snowfall and until 23 October the wind speed remained at $2-4 \mathrm{~m} \mathrm{~s}^{-1}$ for 5 days. Only when it exceeded $6 \mathrm{~m} \mathrm{~s}^{-1}$ on 23 October did snowdrifting begin, as can be seen on the 23 October photograph (Fig. 7). The photographs from 23 and 24 October show that small-scale redistribution of the homogeneous snow cover took place, primarily filling small depressions in the ground surface vegetation layer. This caused levelling of the ground surface, but did not increase the snow depth significantly. After this, more snow fell, and the establishment of a significant snowdrift started on 26 October.

In the centre of the snowpatch at sticks 4 and 3 , the snow depth increased by $80 \mathrm{~cm}$ in 2 days from 24 to 26 October. In this period $8.4 \mathrm{~mm}$ w.e. snow was registered by the heated precipitation gauge. Another $8.7 \mathrm{~mm}$ fell from 26 to 27 October, completely burying stick 4 , where there was $>1.2 \mathrm{~m}$ of snow, while at stick 3 the snow depth was only $90 \mathrm{~cm}$. From 24 to 26 October only $20 \mathrm{~cm}$ of snow accumulated on the upper snowpatch backwall at stick 2. Downwind of the snowpatch the thickness of the snow layer was reduced, and the snow depth was only about $2 \mathrm{~cm}$. Comparing the different snow-depth curves from the snowpatch area with the snow depth on level ground at the nearby meteorological station (Fig. 6) shows that the snowpatch received much more snow than on level ground, while the areas downwind of the snowpatch were deprived of snow, as this was accumulated in the snowpatch.

At stick 3, the snow depth was reduced by $30 \mathrm{~cm}$ to $60 \mathrm{~cm}$ depth from 27 to 28 October, due to snowdrifting. It then increased, particularly during the period 28-30 October when the wind speed was around $10 \mathrm{~m} \mathrm{~s}^{-1}$, and there was $110 \mathrm{~cm}$ of snow on 2 November. Only on 9 November did the snow depth increase above the $120 \mathrm{~cm}$ long stick, contemporarily with the second longer period with strong northerly winds of up to $13 \mathrm{~m} \mathrm{~s}^{-1}$ and a large snowfall of $29.5 \mathrm{~mm}$ w.e.

On the upper part of the snowpatch backwall at stick 2, the snow depth seems to have been stable at $20 \mathrm{~cm}$ from 26 October to at least 6 November. It was not possible to read the snow depth at this stick again until 10 November, when the snow depth reached $60 \mathrm{~cm}$. Presumably, this increase is due to new snowfall and increased snowdrift, and did not take place before the second longer period with strong northerly winds and snowfall started around 8 November. This stick was completely snow-covered on 13 November.

During the three periods with strong winds, the air temperature reached $0^{\circ} \mathrm{C}$ or slightly above (Fig. 6). This did not prevent snowdrifting, which is shown to have taken place during and after these periods.

Some additional data were also obtained on snowpatch distribution after the winter darkness period. Until 23 November, when the dark period began, the snowpatch still had not grown beyond stick 5 , but had its front immediately upwind of this stick. By 25 January, when the first photograph with enough light was taken after the winter darkness, the lower snowpatch front still had not reached stick 6 , where the snow thickness was only about $5 \mathrm{~cm}$, but stick 5 was completely snow-covered. On 1 February the snow-

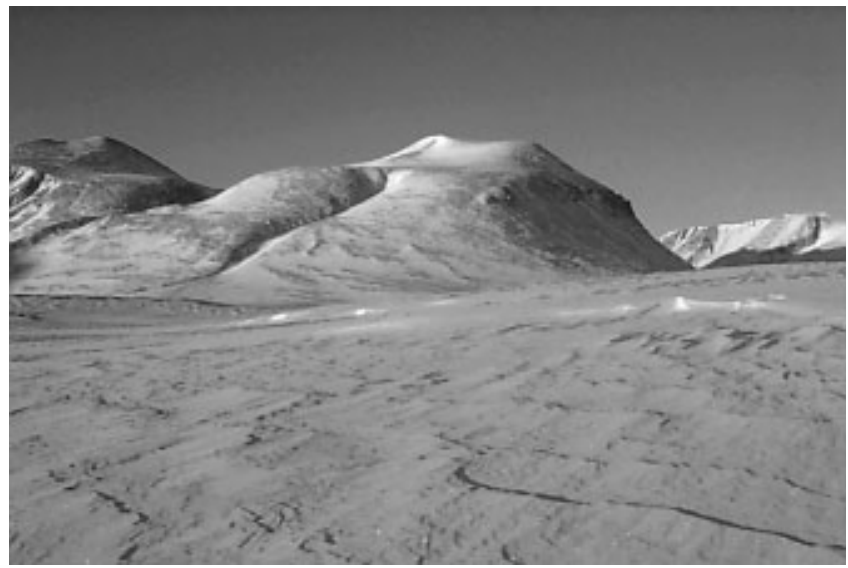

Fig. 8. Automatic digital photograph, 22 February 1998, after a period with snowdrift. Only 4 days later, the camera was completely buried in snow for the rest of the winter.

patch front was still some metres in front of stick 6, while on 2 February it had moved several meters beyond this stick, which now had a $60 \mathrm{~cm}$ snow cover. Snowdrifting took place during February (Fig. 8), and on 25 February stick 6 became completely buried in snow. Comparing the photographs from 24-25 February, it seems that the entire snowpatch surface was raised by $>1 \mathrm{~m}$, probably closer to $2 \mathrm{~m}$, of snow during this one day. On the following day the camera was completely buried in snow, and it stayed snow-covered for the rest of the winter, until 10 June.

\section{SNOW-GOVER DURATION}

The characteristic vegetation zones around the snowpatch on the photograph (Fig. 2) are widespread in the Zackenberg area. The duration of the winter snow cover into the growing season is the major control on the location of the vegetation zones (Christiansen, 1998b). Therefore, to be able to measure the average snow-cover duration at the edges of these zones is also useful for obtaining more overall snow-cover duration data from larger parts of the Zackenberg area.

Based on the photographs, the snowpatch duration in the different vegetation zones at the sticks (Fig. 2) was determined for the 1998/99 season. In the Cassiope tetragona zone, snow covered the ground from 251 days at the upper edge to 280 days at the lower edge, whereas in the Salix arctica zone the snow cover lasted from 280 to $>325$ days at the lower edge, where the snowpatch did not melt in summer 1999. In the moss dominated zone below, the snowpatch lasted from $>238$ days at the lower border to $>325$ days at the upper border. In the forefield grass zone, between sticks 5 and 6 , the snow cover lasted from $>238$ days to 170 days. At the meteorological station, where the vegetation is dominated by Cassiope tetragona, snow remained on the ground for 260 days during winter 1998/99.

These results, together with snow-depth and -distribution data, show that the snowpatch starts accumulating on the lower part of the backwall at stick 4, then grows upwards along the backwall to stick 3, and after some time reaches stick 2. Not until the lee slope on the backwall was completely filled did the snowpatch start growing further downslope to sticks 5 and 6 . Ablation, by contrast, is a homogeneous process occurring horizontally over the entire snowpatch. Therefore, the last snow in summer is left where the snowpatch has been thickest in the moss zone, between sticks 4 and 5 (Fig. 9). 


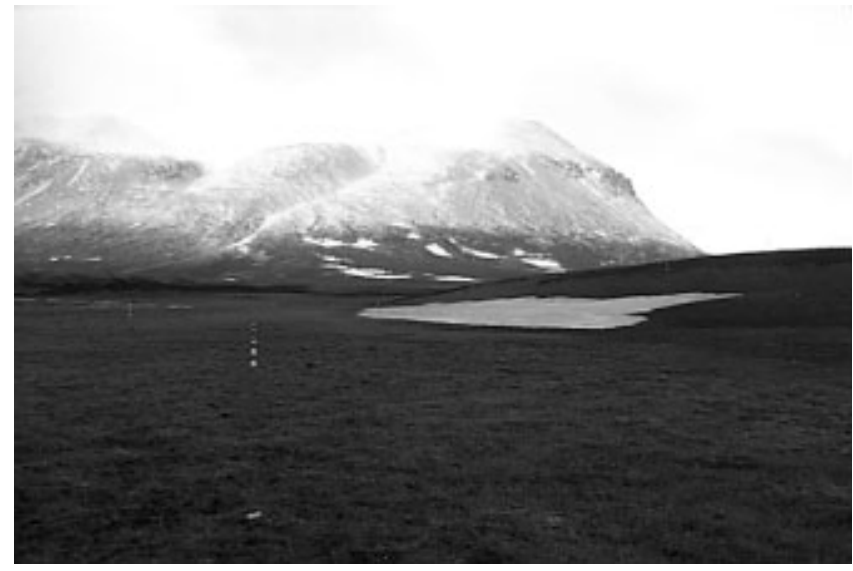

Fig. 9. Automatic digital photograph, 5 September 1999, showing the perennial snowpatch in the central snowpatch area.

The snowpatch ablated significantly through the 1999 summer, but it still existed on 8 September 1999, making it perennial this year, whereas during the previous 4 years it had been only seasonal.

\section{RESULTS AND PERSPEGTIVES}

The work presented shows a new way of obtaining daily data on snow depth, distribution and duration from a snowpatch site using automatic digital on-site photography. These results, combined with standard meteorological data, lead to information on snowdrift-controlling parameters for the high-Arctic Zackenberg site.

The wind-speed threshold for significant snowdrifting to start seems to be around $6 \mathrm{~m} \mathrm{~s}^{-1}$ (at $2 \mathrm{~m}$ height). Large snowdrifting can take place at wind speeds of $>8 \mathrm{~m} \mathrm{~s}^{-1}$, particularly when enough snow is available in the upwind area. In central parts of snowpatches a snow-depth increase of up to $40 \mathrm{~cm} \mathrm{~d}^{-1}$ has been measured during snowdrifting.

The Cassiope tetragona vegetation zone on the snowpatch backwall was snow-covered for 251-280 days. Snow stayed on the ground for $>325$ days in the central snowpatch area. Downwind of the snowpatch, in the grass-dominated zone, the permanent snow cover lasted 238-170 days. Here snowcover duration is completely controlled by snowpatch growth, compared to topographically level areas outside snowpatch-affected areas, as at the meteorological station. There is a variation of up to 155 days in snow-cover duration between the snowpatch and the areas downwind of it. Likewise, in the areas downwind of the snowpatch the snow-cover duration was reduced by up to 90 days compared to level ground, represented by the meteorological station area. Thus, any change in the meteorological parameters controlling snow distribution, such as winter wind speed and direction, amount of precipitation and air temperature, will presumably cause the largest effect on snow-cover duration at the snowpatches and associated downwind areas, whereas the change will be least on level ground.

The snow data presented represent a new way of obtaining detailed datasets for improved testing of physical numerical snow-transport models such as SnowTran-3D (Liston and Sturm, 1998) at much-reduced costs. Apart from the results on snow depth, snowpatch distribution and duration, the automatic photographs can also be used to obtain information on meteorological parameters not included in this work. If the data on snow depth and duration are combined with the ground surface temperatures recorded at the different sticks in the photographed snowpatch, the influence of snow depth on ground surface temperature can be further investigated, explaining observed differences of up to $10^{\circ} \mathrm{C}$ in the mid-winter bottom of snow temperatures in the various parts of the photographed snowpatch in winter 1998/99.

Based on the first year of photographs, some improvements could increase the use of future data. Higher sticks would enable snow-depth curves to be established for longer parts of the winter. Likewise, a higher resolution of the digital photographs, demanding larger storage capacity, which the next generation of digital cameras already have, would improve the quality of the snow-depth data.

To improve knowledge of the effects of changes in the controlling meteorological parameters on snowdrift activity, it is useful to obtain the interannual variations in the timing of snowpatch accumulation, ablation, snow depths, distribution and duration. Presumably, the first year of photographs documented an extreme situation as the snowpatch turned perennial.

\section{AGKNOWLEDGEMENTS}

My best thanks go to chief technician U. P. Thomas, Institute of Geography, University of Copenhagen, who made this idea become reality by developing and testing the automatization of the digital camera and designing the housing. Technician P. Christiansen, also at the Institute of Geography, University of Copenhagen, assisted Ulf. ZERO kindly provides the ClimateBasis monitoring data at the disposal of researchers working in the Zackenberg area. The data are quality-checked by ASIAQ, the Greenland field investigations in Nuuk, Greenland, and are distributed by the Zackenberg research station manager, M. Rasch, Institute of Geography, University of Copenhagen.

This work is part of a study on "Dynamics of high-Arctic soils: Physical and chemical processes in the active layer permafrost system" in the research project "The Arctic Landscape: Interactions and feedbacks among physical geographical and biological processes" funded by the Danish Science Research Councils special programme for polar science, and by the Commission for Scientific Investigations in Greenland. The University Courses on Svalbard (UNIS) kindly provided me with an office while I wrote and revised this paper. The Institute of Geography, University of Copenhagen, supported my participation in the IGS symposium in Innsbruck where this paper was presented.

\section{REFERENGES}

Christiansen, H. H. 1996. Nivation forms, processes and sediments in recent and former periglacial areas. Geogr. Hafniensia A4. (Ph.D. thesis)

Christiansen, H. H. 1998a. "Little Ice Age" nivation activity in northeast Greenland. Holocene, 8(6), 719-728.

Christiansen, H. H. 1998b. Nivation forms and processes in unconsolidated sediments, northeast Greenland. Earth Surf. Processes Landforms, 23(8), $751-760$.

Christiansen, H. H. 1999. Active layer monitoring in two Greenlandic permafrost areas: Zackenberg and Disko island. Dan. F. Geogr., 99, 117-121.

Liston, G. E. and M. Sturm. 1998. A snow-transport model for complex terrain. f. Glaciol., 44(148), 498-516.

Rasch, M., ed. 1999. Zackenberg ecological research operations. 4th annual report, 1998. Copenhagen, Ministry of Research and Information. Danish Polar Center. 